\title{
Ferramentas diamantadas para usinagem de madeira
}

Diamond tools for wood processing

\author{
Jesum Alves Fernandes \\ Mestre em Ciências dos Materiais - UFRGS \\ Av. Bento Gonçalves, 9500 \\ 91501-970, Porto Alegre, RS, Brasil \\ jsmfernandes@yahoo.com.br \\ Carlos Alberto Medeiros Casanova \\ Mestre em Engenharia, Escola de Engenharia - FURG \\ Rua Alfredo Huch, 475 \\ 96201-900, Rio Grande, RS, Brasil \\ carloscasanova@furg.br \\ Cleiton Rodrigues Teixeira \\ Doutor em Eng. Mecânica, Escola de Engenharia - FURG \\ Rua Alfredo Huch, 475 \\ 96201-900, Rio Grande, RS, Brasil \\ cleitonteixeira@furg.br \\ Naira Maria Balzaretti \\ Doutora em Física, Instituto de Física - UFRGS \\ Av. Bento Gonçalves, 9500 \\ 91501-970, Porto Alegre, RS, Brasil \\ naira@if.ufrgs.br
}

\section{Resumo}

O aumento de produtividade da indústria moveleira exige usinagem a altas velocidades de corte e ferramentas que suportem as elevadas exigências do processo de corte. A grande maioria das ferramentas utilizadas atualmente, em geral ligas metálicas, não apresentam as características adequadas, desenvolvendo alto desgaste na cunha de corte. A heterogeneidade da estrutura e a disposição irregular das fibras associada a característica altamente abrasiva da madeira são os principais fatores para ocorrência dos elevados desgastes. $\mathrm{Na}$ solução destes problemas é freqüentemente empregada ferramentas de corte com revestimentos de alta resistência ao desgaste. Nesse sentido, o uso de filmes de diamante depositados por CVD (Chemical Vapor Deposition) apresentam alto potencial de sucesso, pois combina elevada dureza, baixo coeficiente de atrito, alta condutividade térmica e elevada inércia química. Porém, este tipo de ferramentas ainda não é utilizado em escala industrial devido principalmente à baixa adesão entre o filme e o substrato. Este trabalho tem por

\section{Abstract}

The increase in productivity of the furniture industry requires high speed machining and cutting tools to support the high demands of the cutting process. Most of the cutting tools do not have appropriate characteristics and develop high wear on the wedge cut. The heterogeneous structure and irregular arrangement of fibers associated with highly abrasive characteristic of wood are the main factors for the occurrence of high wear. In solving these problems are frequently used cutting tools with coatings of high wear resistance. In this sense, the use of diamond films deposited by CVD (Chemical Vapor Deposition) is a high potential for success, as it combines high hardness, low coefficient of friction, high thermal conductivity and high chemical inertness. However, this type of tools is not yet used on an industrial scale mainly due to low adhesion between the film and the substrate. This study aims to evaluate cutting tools produced by deposition of diamond films on carbide (WC-Co) substrates with different process parameters (CVD). The evaluation of the tools produced by different deposition conditions has been implemented through systematic tests in turning operation of the wood 
objetivo avaliar ferramentas de corte produzidas por deposição de filmes de diamantes em substratos de metal duro (WC-Co) com diferentes parâmetros de processo (CVD). A avaliação das ferramentas, produzidas por diferentes condições de deposição, foi realizada através de ensaios sistemáticos em operação de torneamento de corpos de prova de madeira itaúba, sendo monitorados os desgastes desenvolvidos na cunha de corte. O comportamento dos desgastes nas ferramentas diamantadas foi comparado com os desgastes desenvolvidos em uma ferramenta de metal duro, empregada como referência. Os resultados obtidos neste trabalho mostram o grande potencial do emprego das ferramentas diamantadas na indústria moveleira.

Palavras-chave: ferramentas de corte, ferramentas diamantadas, usinagem de madeira, deposição de filme de diamante em metal-duro. "itaúba". In the same time was monitored the wear $\left(V b_{\text {máx }}\right)$ developed in the wedge-cut. The wear on diamond tools has been compared with the wear developed in a carbide tool, used as reference. The results of this study show the great potential of the use of diamond tools in the furniture industry.

Key words: cutting tools, diamond tools, machining of wood, deposition of diamond film in hard metal.

\section{Introdução}

A indústria de móveis no Brasil tem uma grande contribuição na distribuição socioeconômica do país. Segundo dados da Associação Brasileira das Indústrias do Mobiliário (Abimóvel) em levantamento realizado no ano de 2007, existem mais de 16.000 empresas no setor moveleiro do Brasil, que empregam mais de 206.000 pessoas. Os estados onde estão localizados os pólos industriais do setor são: Rio Grande do Sul, Santa Catarina, São Paulo, Minas Gerais, Paraná, entre outros. O Brasil a partir de 2006 tem registrado um relativo aumento das exportações de artefatos de madeira (Buainain e Batalha, 2007). Materiais compósitos baseados em madeira, principalmente a cultivada, estão sendo cada vez mais utilizados na indústria moveleira. Existe uma ampla gama destes materiais, desde pranchas de compensados até compósitos de madeira com materiais inorgânicos.

A tecnologia de fabricação empregada na indústria moveleira pode ser dividida em três fatores básicos: características dos processos de fabricação; características das máquinas operatrizes e as ferramentas de corte. As características das ferramentas utilizadas neste setor são de suma importância, pois elas são responsáveis pela qualidade de acabamento dos produtos, pela capacidade de produção e conseqüentemente pelo custo final da peça (Filho, 2004). Por isso, o aumento da qualidade e da vida útil das ferramentas durante os processos de usinagem e fabricação de móveis, é fundamental para que as empresas brasileiras ganhem competitividade com o mercado externo.

Atualmente, os materiais utilizados na transformação da madeira são aços endurecidos, carbetos e compactos de diamante policristalino (PCDs). Dentre eles, os mais comuns são os carbetos de tungstênio dopados com cobalto (WC-Co), pois apresentam boa resistência à abrasão e custo relativamente baixo comparado aos PCDs. Os carbetos podem ser preparados com ângulos de corte apropriados, necessários para conferir melhor qualidade de acabamento da superfície comparativamente aos PCDs. Nos últimos dez 
anos, muitos trabalhos foram realizados nesta área, resultando em um aumento na vida útil das ferramentas através de recobrimentos protetores obtidos através de nitretação, deposição de carbetos e filmes de diamante (Yuhara, 2000; Santos, 2004; Camerini, 2008). Apesar do amplo uso de recobrimentos duros do tipo PVD (Physical Vapor Deposition) e CVD (Chemical Vapor Deposition) para aumentar a resistência à abrasão de ferramentas de corte, até o presente momento, eles não têm sido utilizados na usinagem de madeira por problemas na aderência.

Os principais fatores para o desgaste das ferramentas são as características altamente abrasivas da madeira além de suas descontinuidades estruturais ao longo do caminho de usinagem, podendo causar a falha catastrófica das mesmas (Hilling, 2006). Isso acarreta a queda de produtividade e qualidade, além de maior custo na fabricação de móveis, já que troca de ferramentas são mais constantes e também ocorre a diminuição das velocidades de corte.

Para a solução destes problemas é estudada a utilização de ferramentas diamantadas sobre metal duro, pois combinam propriedades como elevada dureza, baixo coeficiente de atrito, alta condutividade térmica e inércia química. Entretanto, este tipo de ferramentas ainda não é utilizado em escala industrial devido principalmente à baixa adesão entre filme e substrato (Camerini et al., 2009; Santos, 2004).

A análise do desempenho das ferramentas de corte é baseada nas propriedades tribológicas e da erosão da cunha de corte provocado durante o processo de remoção de material, logo as propriedades ímpares do diamante, tais como: extrema dureza, baixo coeficiente de atrito, inércia química, alta condutividade térmica, entre outras propriedades superiores fazem do diamante o material ideal para uso em ferramentas de corte. A técnica de CVD para a síntese de diamante permite recobrir ferramentas com filmes de diamante para operações de usinagem. Vários artigos na literatura descrevem o sucesso da utilização desta tecnologia para a usinagem, por exemplo, de ligas de alumínio-silício e de grafite. Entretanto, até o presente momento a implementação desta tecnologia na indústria do processamento da madeira não foi realizada com sucesso. Muitas das importantes aplicações das ferramentas recobertas com filmes de diamante são limitadas pela aderência insuficiente do diamante ao substrato (Camerini et al.; 2009). No caso da usinagem de madeira, este problema é agravado pela necessidade de pequenos ângulos de cunha. A presença de bordas agudas durante a síntese de filmes de diamante em altas temperaturas reduz a tenacidade da aresta e aumenta a tensão compressiva residual no filme de diamante devido à diferença nos coeficientes de expansão térmica do filme e do substrato.

Neste trabalho foram desenvolvidas ferramentas diamantadas para usinagem de madeira a partir da técnica de CVD, onde a geometria do substrato de WC-Co utilizado foi otimizada para minimizar as falhas provocadas por arestas agudas e delaminação dos filmes. Na produção das ferramentas foram empregados diferentes tratamentos superficiais nos substratos antes da deposição do filme de diamante (diferentes ataques ácidos e deposição de intercamadas de titânio). Para avaliação estrutural dos filmes foi utilizada a técnica de espectroscopia Raman. As avaliações quanto à adesão e propriedades mecânicas dos filmes foram realizadas por ensaios de delaminação e testes instrumentados de dureza (HIT). Os testes de usinagem foram realizados em ensaios de torneamento com corpos de provas cilíndricos de madeira Itaúba, sendo 
avaliado o desempenho das ferramentas através da medição do desgaste de flanco ( $\mathrm{Vb}_{\text {Máx }}$ ) e integridade da cunha de corte.

\section{Materiais e Métodos}

A metodologia empregada consiste na fabricação das ferramentas, avaliação da qualidade dos filmes, e a realização de ensaios sistemáticos de usinagem, através da operação de torneamento cilíndrico externo da madeira itaúba.

\subsection{Metal Duro - Substrato}

O metal duro, ou carbeto de tungstênio (WC), é um dos materiais para ferramentas de corte mais utilizados e importantes na indústria, devido suas elevadas propriedades tais como: elevado valor de dureza à temperatura ambiente e à quente, alta tenacidade, grande resistência ao desgaste, entre outras características. Estas propriedades se devem principalmente à possibilidade de variação de sua composição (efeito da fase ligante). A fabricação do metal duro é realizada a partir da metalurgia do pó, e o processo é baseado na mistura de pós cerâmicos e metálicos prensados em pastilhas ou em cilindros para fabricação de brocas e fresas inteiriças. A partir desta etapa é realizada a pré-sinterização onde o material obtém consistência para permitir execução da forma desejada. Após é realizado o processo final de sinterização da peça e realizado o acabamento quando necessário (Santos, 2004). O metal duro é composto basicamente de carbeto de tungstênio e, em geral, é conjugado com outros carbetos, de titânio (TiC), tântalo (TaC) e nióbio $(\mathrm{NbC})$, porém este último em pequenas proporções em relação aos demais. Outro elemento fundamental na produção do metal duro é o agente ligante, pois ele é o responsável por aglomerar as partículas dos carbetos. O cobalto (Co) é geralmente utilizado como agente ligante na confecção do metal duro. De maneira geral, as porcentagens dos conjugados e do ligante irão conferir as propriedades finais do produto, sendo cada composição classificada conforme a norma ISO (Santos, 2004).

Outros fatores que também devem ser analisados nas ferramentas de metal duro são o tamanho de grão e a porosidade, pois afetam diretamente a capacidade de corte da ferramenta. De maneira geral pode-se afirmar que quanto maior o tamanho de grão, menor é a resistência ao desgaste e a tenacidade do metal duro, entretanto, maior será à resistência mecânica do material. A porosidade está ligada diretamente à densidade do metal duro, ou seja, quanto menos poros o material mais denso será, o que conseqüentemente trará melhoras nas suas propriedades mecânicas.

As velocidades de cortes de uma ferramenta de metal duro em madeira ficam em uma faixa de $35 \mathrm{~m} / \mathrm{s}-$ 75 m/s (Filho, 2004). O metal duro é normalmente utilizado como substrato para revestimentos cerâmicos quando as velocidades de corte produzidas ultrapassam estes valores. Uma das limitações de sua utilização como substrato, por exemplo, do diamante é a fraca adesão entre substrato e filme pela necessidade de remoção do agente ligante nas primeiras camadas do substrato (Camerini, 2008). 


\subsection{Filme de Diamante}

Nas condições normais de temperatura e pressão o carbono apresenta a fase cristalina da grafita, com rede hexagonal contendo átomos com ligações $\mathrm{sp}^{2}$. O diamante apresenta fase cristalina cúbica de face centrada onde o carbono forma ligações $\mathrm{sp}^{3}$ e é a fase estável do carbono em altas pressões (Santos, 2004).

A barreira cinética para transformação de fase entre grafita e diamante é elevada, pois envolve mudança na hibridização dos átomos e um rearranjo estrutural de uma fase bidimensional para uma tridimensional.

Os filmes de diamante são produzidos através da técnica de deposição química a vapor em uma região de metaestabilidade termodinâmica, pois o processo ocorre em altas temperaturas e baixas pressões. Este processo basicamente é realizado pela dissociação de moléculas em uma atmosfera rica em hidrogênio. A dissociação das moléculas pode ser realizada usualmente pelas seguintes formas: tocha de acetileno; filamento aquecido; plasma gerado por microondas, radiofreqüência ou descarga por corrente contínua. Após a dissociação das moléculas através de convecção, difusão e gradientes térmicos essas espécies seguem para o substrato dando início ao filme de diamante. Neste trabalho foi empregada a técnica de CVD ativada por microondas. Neste tipo de processo as características dos filmes de diamante produzidos estão intimamente ligadas às condições de pressão, temperatura e as propriedades do substrato utilizado. Em geral, durante este processo de deposição o metano $\left(\mathrm{CH}_{4}\right)$, tipicamente $1 \%$, é utilizado como fonte de carbono, o hidrogênio $\left(\mathrm{H}_{2}\right)$, em grande quantidade, possui inúmeras funções descritas a seguir, e ainda pode ser utilizado oxigênio $\left(\mathrm{O}_{2}\right)$, neste caso 10 \%, para acelerar a taxa de deposição (Silva, 1997; Santos, 2004).

Dentre as funções do $\mathrm{H}_{2}$, ele é responsável em conjunto com a fonte de microondas pela ativação do plasma, onde ocorrerá todo o processo de ativação das espécies químicas. Após a estabilização do plasma é adicionado o gás carbonáceo e, quando necessário oxigênio. A temperatura no plasma pode atingir $5000^{\circ} \mathrm{C}$ dependendo da potência utilizada. A partir desta etapa ocorre à dissolução de carbono, na presença de $\mathrm{H}$ atômico formado no processo de ativação do plasma.

Através de um processo de convecção e gradientes térmicos no interior da câmara, o carbono resultante da dissolução do $\mathrm{CH}_{4}$ é dirigido ao substrato que geralmente está à temperatura entre $800^{\circ} \mathrm{C}-1000^{\circ} \mathrm{C}$, $\mathrm{O}$ que fica dependente da potência empregada no processo. O substrato fica em uma base refrigerada com água circulante para evitar seu aquecimento a temperaturas próximas do ponto de fusão do material em questão. A partir de flutuações estatísticas são produzidos os primeiros núcleos de diamante, bem como grafite e carbono amorfo. Entretanto, pela alta quantidade de $\mathrm{H}$ atômico no interior da câmara, acredita-se que ocorre um ataque seletivo do mesmo fazendo com que a fase de diamante ( $\mathrm{sp}^{3}$ ) prevaleça (Silva, 1997; Santos, 2004).

No Brasil, a deposição de filme de diamante na região termodinamicamente metaestável foi implantada de forma pioneira no Laboratório de Altas Pressões e Materiais Avançados-LAPMA-UFRGS. O primeiro processo foi realizado através da técnica de CVD ativada por filamento quente e, subseqüentemente, sendo também realizada através de um reator CVD ativado por microondas (Camerini et al., 2009).

O crescimento dos núcleos de diamante ocorre após a nucleação, podendo se dividir em duas etapas. $\mathrm{Na}$ primeira delas, as partículas aumentam o seu tamanho até se tocarem, recobrindo toda a superfície do 
substrato; este processo é chamado de coalescência dos grãos. A segunda etapa é o crescimento propriamente que ocorre até o final do experimento, o que definirá a espessura resultante do filme. As condições de deposição (pressão e temperatura do plasma) definirão o crescimento preferencial das famílias de planos $\{111\}$ e $\{100\}$ do diamante (Fritzen, 1996; Lucchese, 2006). Concomitante à fase de crescimento, pode continuar a ocorrer nucleação de diamante.

\subsection{Adesão do filme de Diamante no Metal Duro}

A adesão de filmes de diamante em substratos de WC-Co vem sendo muito estudada nos últimos anos devido ao grande interesse para aplicações tecnológicas. Muitos pesquisadores vêm realizando trabalhos nesta área a fim de conseguir uma boa adesão entre filme e o substrato (Silva, 1997; Camerini et al., 2009). A baixa aderência especificamente neste caso se deve a inúmeros fatores, especialmente:

\section{(a) Barreira formada pelo cobalto nas camadas superficiais}

A presença do Co nas primeiras camadas da superfície do substrato, que em contato com o plasma, impede a formação de diamante, pois privilegia a formação de ligações $\mathrm{sp}^{2}$. Este tipo de problema em geral é solucionado de duas formas: remoção do Co por ataque químico ou deposição de intercamadas de metais refratários na superfície do substrato.

\section{(b) Diferença do coeficiente de dilatação térmica entre o substrato e o filme}

O diamante tem um baixo coeficiente de dilatação térmica, em geral menor que o substrato. Isto se torna crítico, pois durante o processo de deposição a superfície do substrato chega a elevadas temperaturas (700 $\mathrm{C}^{\circ}-1000 \mathrm{C}^{\circ}$ ) podendo ocasionar um tensionamento térmico significativo durante a diminuição da temperatura no final do processo de deposição, levando à delaminação total do filme de diamante. Desta forma é muito importante que o término do processo seja realizado lentamente, evitando o agravamento de possíveis tensões térmicas.

\section{(c) Densidade de nucleação}

A baixa densidade de nucleação também pode afetar a adesão do filme de diamante, pois os núcleos ficam separados a uma distância muito grande o que pode gerar vazios entre os grãos após o término da fase de nucleação. Este fator deverá facilitar possíveis formações e propagação de trincas na interface.

\section{(d) Distorções da rede cristalina}

Devido à diferença dos parâmetros de rede e morfologia entre filme e substrato a deposição das primeiras camadas do diamante pode ser acompanhada pela geração de defeitos na sua rede cristalina, facilitando a criação e propagação de trincas. Estes defeitos são causados para acomodar as diferenças de parâmetros de rede para permitir o crescimento do filme a partir de ligações primárias.

\subsection{A Madeira}

A madeira pode ser descrita de maneira geral como sendo um composto formado pelo tecido xilemático, complexamente composto, dos vegetais superiores que é encontrado em troncos e galhos. Estes possuem 
células especializadas na sustentação e condução da seiva. As principais células encontradas no xilema são as fibras, elementos de vasos, raios, traqueídeos, parênquima axial e algumas estruturas especiais definidas por cada família. As propriedades mecânicas da madeira são definidas em função da aptidão industrial que é determinada pela resistência à compressão axial e cisalhamento na direção paralela as fibras, flexão estática, módulo de elasticidade, resistência a impactos e choques, dureza superficial, os quais são importantes para o processo de usinagem (Filho, 2004).

Existem dois fatores importantes que afetam significativamente o processo de usinagem da madeira, a irregularidade estrutural natural das madeiras e o teor de umidade. A irregularidade na disposição das fibras e veios provoca uma anisotropia em suas propriedades. Com a redução da umidade, alguns elementos químicos existentes na seiva acabam ficando cristalizados entre as fibras, afetando a atuação das ferramentas de corte nos processos de usinagem.

A madeira escolhida para os testes neste trabalho foi a itaúba, seu nome científico é Mezilaurus itauba pertencente à família lauraceae. Seus nomes comerciais no Brasil são: itaúba, louro-itaúba, itaúba-amarela, itaúba-abacate e itaúba-preta. A Itaúba tem como características gerais ser uma madeira relativamente pesada, dura, de difícil usinagem, podendo ter excelente acabamento, textura média e uniforme, elevada resistência mecânica e alta durabilidade, tendo cheiro adocicado.

\subsection{Processo de Usinagem}

O processo de corte pode ser definido a partir do cisalhamento do material em questão, onde expõe a ferramenta a grandes tensões mecânicas, dinâmicas, térmicas e tribológicas. Para tanto é necessário que a ferramenta possua uma combinação de propriedades superiores como elevada dureza, resistência à abrasão entre outras características. O grau de exigência da ferramenta é função direta do material a ser usinado. Os principais mecanismos de desgaste que atuam normalmente nas ferramentas de corte são a adesão, a abrasão, a difusão e a oxidação (Konig, 1990).

\section{Procedimento Experimental}

\subsection{Preparação do Substrato}

Para o processo de deposição dos filmes de diamante CVD sobre metal duro é necessária a realização de tratamentos superficiais nas amostras, como já foi descrito anteriormente. Neste trabalho foram realizados dois processos de tratamentos superficiais: ataques químicos e deposição de intercamadas de titânio.

Os ataques químicos para a remoção do cobalto superficial foram realizados em três diferentes condições:

Ataque 1: primeiramente foi realizada uma semeadura nas amostras através do processo de polimento com pasta de diamante de granulometria da ordem de $1-2 \mu \mathrm{m}$ por 3 minutos. Este polimento aumenta a taxa de nucleação de diamante. Após esta etapa as amostras foram atacadas com solução de $50 \%$ vol $\mathrm{HF}+$ $50 \%$ vol $\mathrm{HNO}_{3}$ por 6 minutos em ultra-som para limpar a superfície de deposição. Para a remoção do cobalto presente na superfície foi utilizada uma solução de $30 \%$ vol $\mathrm{H}_{2} \mathrm{SO}_{4}+70 \%$ vol $\mathrm{H}_{2} \mathrm{O}_{2}$ durante diferentes tempos 
de ataque: 5, 10, 20 e 50 segundos em ultra-som. Finalmente as amostras foram limpas através de banho em ultra-som com água deionizada por 5 minutos (Camerini, 2008).

Ataque 2: neste tratamento as amostras primeiramente foram limpas com solução de Murakami (10g $\left.\mathrm{K}_{3}\left(\mathrm{Fe}(\mathrm{CN})_{6}\right)+10 \mathrm{~g} \mathrm{KOH}+100 \mathrm{ml} \mathrm{H} \mathrm{H}_{2} \mathrm{O}\right)$ por 5 minutos em ultra-som. Na segunda etapa as amostras foram atacadas com solução de $10 \%$ vol $\mathrm{HNO}_{3}+90 \%$ vol $\mathrm{H}_{2} \mathrm{O}_{2}$ por 60 segundos em ultra-som a fim de remover o cobalto da superfície. Finalmente as amostras foram limpas através de banho em ultra-som com água deionizada por 5 minutos. Na última etapa foi realizada a semeadura das amostras em ultra-som por 15 minutos, com partículas de diamante de $1 / 2 \mu$ m suspensas em uma solução de $20 \% \mathrm{volC}_{2} \mathrm{H}_{5} \mathrm{OH}+80 \%$ ol $\mathrm{H}_{2} \mathrm{O}$ com uma concentração de 50 I/quilate (Cabral, 2008).

Ataque 3: neste tratamento também foi utilizada a solução de Murakami em ultra-som por 15 minutos para limpeza. Para a remoção do cobalto foi realizado com solução de $3,5 \%$ vol $\mathrm{H}_{2} \mathrm{SO}_{4}+96,5 \%$ vol $\mathrm{H}_{2} \mathrm{O}_{2}$ por 10 segundos em ultra-som. Ao final destas duas etapas as amostras foram limpas através de banho em ultra-som com água deionizada por 05 minutos A semeadura das amostras foi realizada em ultra-som por 15 minutos, com partículas de diamante de $1 / 2 \mu \mathrm{m}$ suspensas em uma solução de $20 \%$ volC $\mathrm{H}_{5} \mathrm{OH}$ $+80 \% \mathrm{volH}_{2} \mathrm{O}$ com uma concentração de 50 l/quilate (Polini, 2008). Para facilitar a identificação das amostras elas foram nomeadas conforme o tipo de ataque químico utilizado para remoção do cobalto e o tempo de exposição conforme a Tabela 1.

Tabela 1: Denominação dada para amostras atacadas quimicamente para remover o Co superficial.

\begin{tabular}{ccc}
\hline Nome Amostras & Solução Ácida & $\begin{array}{c}\text { Tempo de Remoção do Co } \\
\text { [segundos] }\end{array}$ \\
\hline Atq1_05 & & 05 \\
Atq1_10 & Ataque 1 & 10 \\
Atq1_20 & & 20 \\
Atq1_50 & Ataque 2 & 50 \\
Atq2_60 & Ataque 3 & 60 \\
Atq3_10 & & 10 \\
\hline
\end{tabular}

A inserção da intercamada de titânio foi utilizada para impedir a migração do cobalto para a superfície de deposição do filme de diamante CVD. Esta amostra foi nomeada da seguinte forma: Ti_120: nome do revestimento e espessura final aproximada, em nanômetros.

Titânio: Para a deposição dos filmes de titânio $(128 \mathrm{~nm})$ os substratos foram polidos mecanicamente com pasta de diamante desde a granulometria de $30 \mu \mathrm{m}$ até $1 \mu \mathrm{m}$. As amostras foram limpas com acetona P.A. e água deionizada em banho de ultra-som por 15 minutos em cada etapa. A técnica de deposição utilizada foi de DC magnetron sputtering (Jacobsen, 2007; Tentardini, 2000). 


\subsection{Deposição dos Filmes de Diamante}

O processo de deposição de filmes de diamante foi realizado através da técnica de deposição química a vapor ativado por microondas (Microwave Chemical Vapor Deposition - MWCVD), com um equipamento da marca ASTEX AX5000. A configuração do sistema possui uma fonte de potência para geração de microondas na freqüência de $2,45 \mathrm{GHz}$ (A5000), podendo trabalhar com uma potência máxima de até $5 \mathrm{~kW}$. 0 sistema pode atingir uma pressão máxima de 120 Torr utilizando uma bomba de vácuo da marca Edwards com o auxílio de controladores de fluxo de gases. O equipamento também possui um pirômetro Williamson, série 9000, o qual trabalha com comprimentos de ondas de $2,1 \mu \mathrm{m}$ e $2,4 \mu \mathrm{m}$, a fim de medir a temperatura da superfície do substrato. A Figura 1 apresenta a foto do equipamento utilizado no LAPMA.

Os parâmetros de deposição foram mantidos constantes em todas as amostras:

- Pressão: 80 torr

- Potência: 3000 W

- Temperatura média da base do substrato: $210^{\circ} \mathrm{C}$

- Tempo de deposição: 4 horas

- Fluxo de gases: $300 \mathrm{sccm}$ de hidrogênio, $30 \mathrm{sccm}$ de oxigênio e $3 \mathrm{sccm}$ de metano ( $\mathrm{sccm}=$ centímetros cúbicos padrão por minuto). As amostras resultantes nesta etapa, mantém a mesma denominação da Tabela 1.
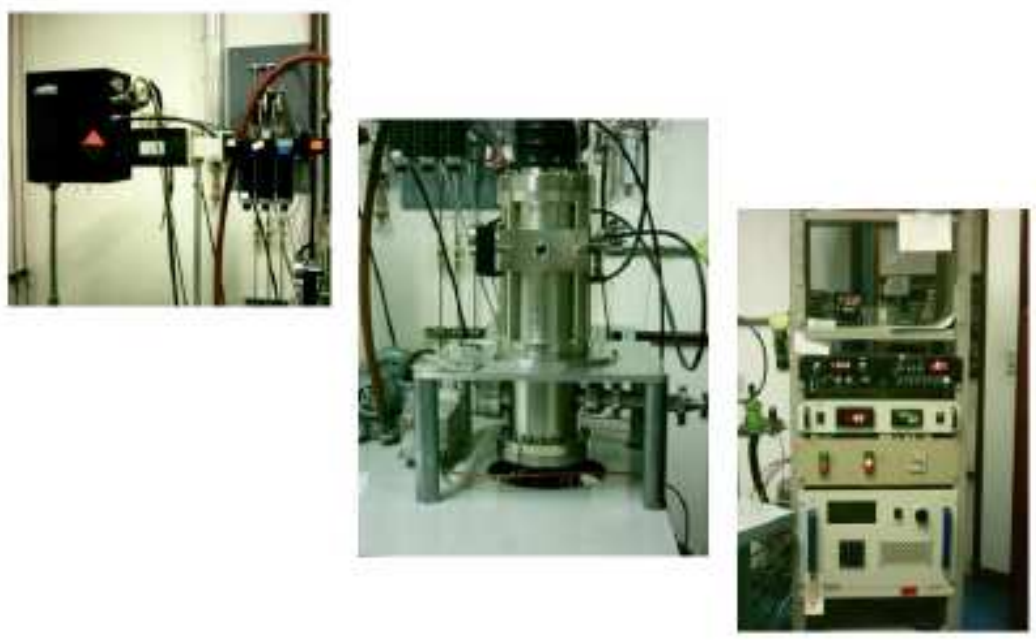

Figura 1: Foto do equipamento utilizado para produção dos filmes de diamante.

\subsection{Espectroscopia Raman}

A análise Raman consiste na incidência de um feixe de laser na amostra onde ocorre um processo de interação e conseqüentemente o espalhamento inelástico da luz incidente. A diferença entre as freqüências 
da radiação incidente e da radiação espalhada está relacionada à freqüência vibracional característica do material, o que constitui no espectro Raman (Camerini et al., 2009). A espectrometria Raman foi utilizada para identificar a presença de diamante e a tensão intrínseca dos filmes de diamante CVD. A presença do diamante é facilmente determinada, pois ele apresenta um único pico agudo e bem definido em $1332 \mathrm{~cm}^{-1}$. A tensão dos filmes é possível determinar através do deslocamento e alargamento do pico Raman do diamante, segundo modelo proposto por Grimsditch et al.(1978).

\subsection{Ensaios de Delaminação}

Estes ensaios foram utilizados para verificar as condições de adesão dos filmes sobre o substrato para os diferentes tratamentos superficiais utilizados. O equipamento utilizado foi um durômetro analógico de bancada da marca AWPMA. Para a realização dos ensaios foi utilizado um indentador Rockwell do tipo cone de diamante, utilizando cargas de 15,2 kgf e 62,5 kgf. A partir das indentações realizadas ocorre o descolamento do filme, este sendo analisado por um MO. Para esta medida determina-se o raio da região delaminada em função dos diferentes tratamentos superficiais realizados.

\subsection{Testes Instrumentados de Dureza}

Os testes instrumentados de dureza foram utilizados neste trabalho a fim de verificar possíveis modificações estruturais nos filmes de diamante CVD a partir dos diferentes tratamentos superficiais realizados.

Atualmente o HIT é uma das técnicas mais utilizadas para avaliar as propriedades mecânicas de filmes. A grande vantagem desta técnica está na forma contínua de incremento da carga, e na conseqüente aquisição dos valores de carga e de profundidade instantâneos a cada ponto (resolução do equipamento de $4 \mu \mathrm{N}$ e $2 \mathrm{~nm}$, respectivamente). Este fato gera valores de dureza e o acompanhamento do comportamento mecânico das amostras imediatos.

Para realização destes testes primeiramente é definida a taxa de aplicação de carga (carga máxima e tempo total de aplicação). Após definidos estes parâmetros um penetrador de geometria conhecida entra em contato com a amostra, sendo aplicada uma carga mínima, para definição do ponto inicial. Após a definição deste ponto inicia-se a aplicação de carga de forma contínua gerando uma curva de carga e descarga conforme a Figura 2.

Outra informação que pode ser extraída do gráfico de profundidade em função da carga aplicada (Figura 2) é o índice de plasticidade $\left(I_{p d}\right)$ das amostras medido segundo a Equação (1):

$$
I_{p d}=1-\frac{\left(h_{m}-h_{f}\right)}{h_{m}}
$$

onde $h_{m}$ e $h_{f}$ são a profundidade máxima e a profundidade final, respectivamente. $O I_{p d}$ revela comparativamente as amostras que obtiveram uma maior contribuição elástica durante as medidas de dureza. 


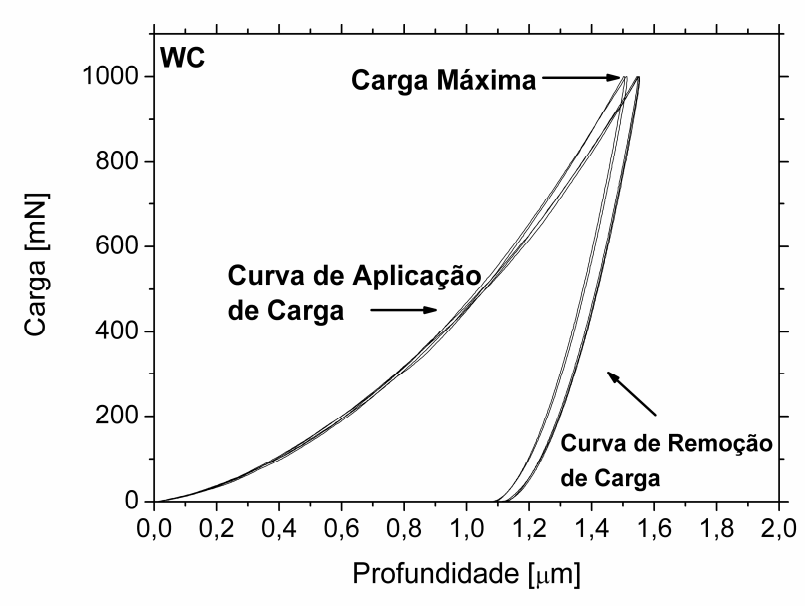

Figura 2: Apresenta o gráfico correspondente à aplicação de um ciclo completo de carga - descarga em um ensaio de dureza através da técnica de HIT.

Neste trabalho foi utilizado um equipamento da marca Fischerscope HV100, com indentador Vickers. A carga máxima utilizada foi de $1 \mathrm{~N}$ com tempo total de carga - descarga de 120 segundos. Foram realizadas no mínimo 5 medidas válidas para cada amostra. Os valores de dureza foram calculados conforme a norma ISO 14577. O equipamento está localizado no Grupo de Estudos em Propriedades de Superfície e Interfaces (GEPSI - PUCRS).

\subsection{Testes de Usinagem}

Os testes de usinagem tiveram por objetivo avaliar o desempenho de um lote de ferramentas de corte produzidas neste trabalho com diferentes tratamentos superficiais, para a usinagem de madeira.

Os corpos de prova foram preparados de madeira itaúba adquirida no mercado, em toras secas (umidade média $5 \%$ em peso), semi-processada, de onde foram preparados cilíndricos com dimensões médias de $145 \mathrm{~mm}$ de diâmetro e $470 \mathrm{~mm}$ de comprimento. As fibras e veios da madeira ficaram dispostos longitudinalmente ao eixo do cilindro (transversalmente ao corte da ferramenta).

O equipamento utilizado foi um torno universal marca Nardini, modelo Mascote MS-205-AS, equipado com réguas ópticas para definição do posicionamento da ferramenta. A montagem realizada devido às dimensões do corpo de prova foi placa e contra-ponto, visando obtenção da rigidez necessária na operação. Os parâmetros utilizados foram: velocidade de corte $285 \mathrm{~m} / \mathrm{min}$., avanço 0,05 mm/volta e profundidade de corte $0,08 \mathrm{~mm}$. A montagem completa do sistema pode ser observada na Figura 3. 


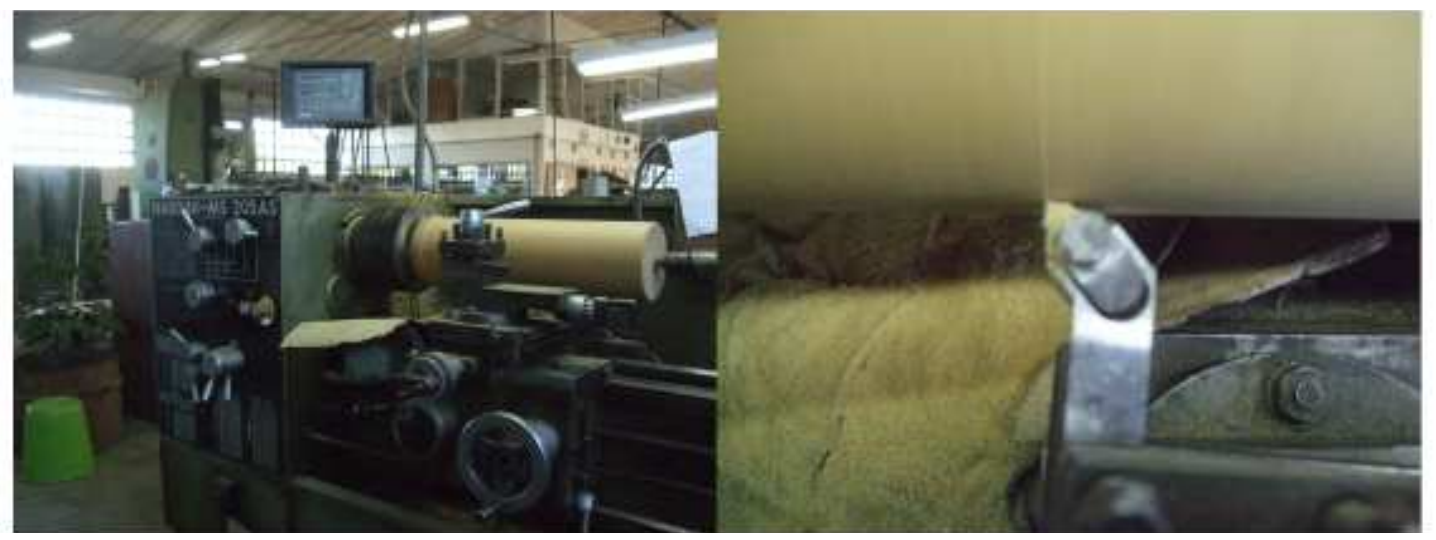

Figura 3: Detalhes da montagem e atuação da ferramenta durante os testes de usinagem.

Os insertos apresentaram uma pequena variação dimensional, ficando com a seguinte geometria: Geometria do inserto: ângulo de ponta $=90^{\circ}$, ângulo de saída $=0^{\circ}$ e ângulo de folga $=0^{\circ}$. Os ângulos efetivos de trabalho na máquina foram: ângulo de posição principal $=80^{\circ}$, ângulo de saída $=-10^{\circ}$ e ângulo de folga $=10^{\circ}$. Os testes foram realizados com a usinagem de um corpo de prova por amostra, a fim de permitir a manutenção dos parâmetros de corte ao longo do ciclo de trabalho (vida da ferramenta). A medição dos desgastes foi realizada através de um sistema de medição digital com registro das imagens nos intervalos de tempo pré-definidos, com o monitoramento da superfície de saída (desgaste de cratera - Kt) e da superfície de incidência (desgaste de flanco - VB), utilizando o desgaste que apresentar predominância (Schroeter e Teixeira, 2000). O critério de fim de vida aplicado foi a vida de 195 min. Os pontos definidos para as medições foram:

- Ponto 1 - ferramenta nova sem uso;

- $\quad$ Ponto 2 - ferramenta com 15 min. de trabalho;

- $\quad$ Ponto 3 - ferramenta com 60 min. de trabalho;

- $\quad$ Ponto 4 - ferramenta com 105 min. de trabalho;

- $\quad$ Ponto 5 - ferramenta com 150 min. de trabalho;

- Ponto 6 - ferramenta com 195 min. de trabalho.

\section{Resultados}

A Figura 4 apresenta os resultados das medidas de tensão através da poespectroscopia Raman e também análises qualitativas de adesão. Analisando os resultados podemos verificar uma correlação inversa para as amostras que sofreram ataques químicos. As amostras atacadas quimicamente que obtiveram os maiores valores de tensão (Atq1) apresentaram a menor região delaminada. Este mecanismo pode ter ocorrido devido à forte ligação entre substrato-filme, ocasionando um tensionamento na estrutura dos filmes. Nas amostras que apresentaram uma região de maior delaminação (Atq2_10 e Atq3_60), provavelmente os 
filmes estavam um pouco menos aderidos ao substrato, o que ocasiona um relaxamento maior da estrutura dos filmes. Entretanto, a amostra Ti_120 obteve um comportamento inverso ao encontrado para o restante das amostras, ou seja, alto valor de tensão e uma grande região delaminada, provavelmente devido ao efeito combinado das duas regiões de interface.
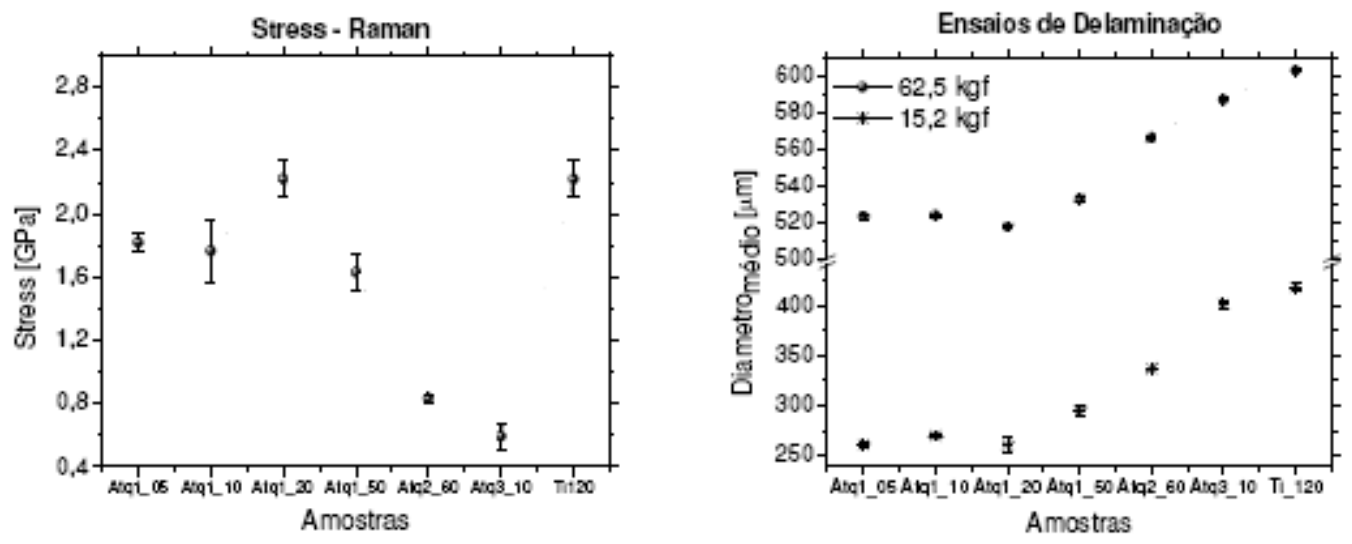

Figura 4: Resultados das medidas de tensão e dos ensaios de delaminação nas ferramentas.

A Figura 5 e a Tabela 2 apresentam os resultados dos testes instrumentados de dureza e dos ensaios de usinagem, respectivamente. O desempenho das ferramentas foi monitorado através do desgaste predominante, no caso o desgaste na superfície de folga $\left(V B b_{M a x}\right)$. Na relação entre os testes instrumentados de dureza e os ensaios de usinagem as amostras Atq1_50 e Ti_120 apresentaram comportamentos diferenciados em relação às outras amostras. Apesar de obter o menor valor de dureza a amostra Atq1_50 apresentou uma melhora significativa, em relação ao substrato, na resistência ao desgaste. Isto pode ter ocorrido por esta amostra apresentar uma boa resposta elástica com um $I_{p d}$ de aproximadamente $30 \%$. Isto indica que, apesar do composto filme-substrato ter obtido um baixo valor de dureza, no processo de usinagem este mecanismo não influenciou de modo significativo, sugerindo que o fator de maior influência pode ter sido o índice de plasticidade do composto filme-substrato. A amostra Ti_120 também apresentou uma relação diferenciada, obtendo um valor de dureza e de $I_{p d}$ intermediário e um elevado desgaste da ferramenta. Neste caso a geração deste efeito pode estar ligada à influência do número de interfaces da amostra ocasionando uma interferência destrutiva ou construtiva nos resultados dependo do tipo de ensaio.

Para o restante das amostras a relação entre os testes instrumentados de dureza e os ensaios de usinagem ocorreu como era esperado nestes casos, ou seja, baixos valores de dureza e alto índice de plasticidade resultaram em um alto valor de desgaste. As amostras Atq1_05 e Atq1_10 que apresentaram os menores valores de dureza e os maiores $I_{p d}$ obtiveram um desgaste significativamente maior em relação as amostras Atq1_20, Atq3_10 e Atq2_60. As amostras Atq1_20 e Atq3_10 que apresentaram elevados valores de dureza e obtiveram um índice de plasticidade da ordem de $30 \%$ apresentaram uma diminuição significativa no desgaste da ferramenta em relação ao substrato. Entretanto, a amostra Atq2_60 que 
também apresentou um elevado valor de dureza, porém o menor índice de plasticidade dentre todas as amostras, foi a que obteve o menor valor de desgaste durante os ensaios de usinagem. A combinação de elevada dureza e baixo grau de deformação plástica parece ser a ideal para ferramentas para usinagem de madeira.

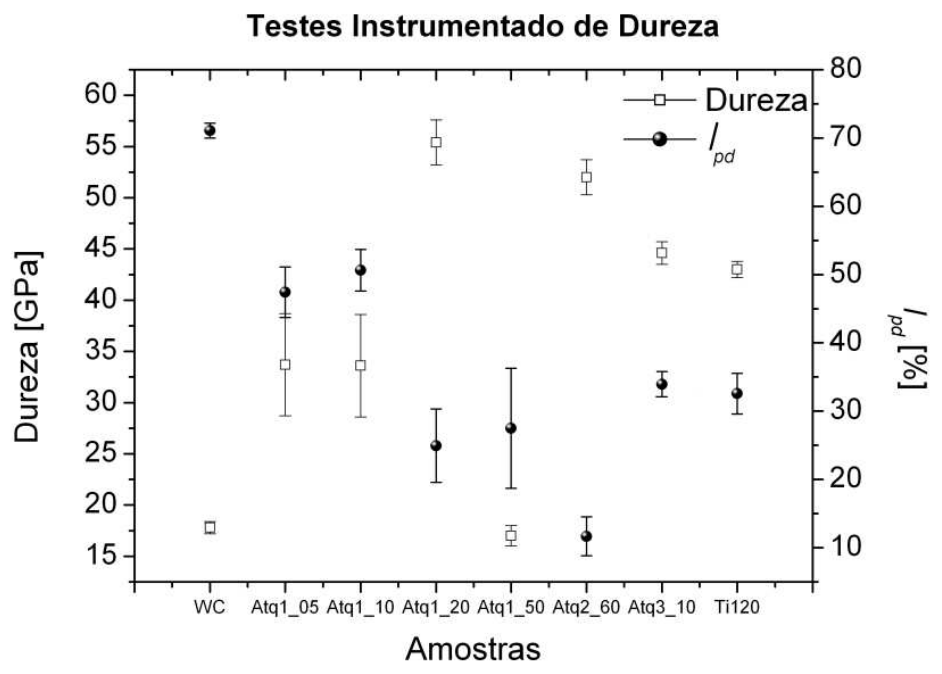

Figura 5: Resultados dos testes instrumentados de dureza.

Tabela 2: Resultados dos testes de usinagem, desgastes VBb Máx em função do tempo de trabalho da ferramenta.

\begin{tabular}{ccccccc}
\hline & \multicolumn{5}{c}{ Pontos de medição } \\
\cline { 2 - 7 } Amostras & & $\begin{array}{c}(1) \\
15 \mathrm{~min} . \\
{[\mathrm{mm}]}\end{array}$ & $\begin{array}{c}(2) \\
60 \mathrm{~min} . \\
{[\mathrm{mm}]}\end{array}$ & $\begin{array}{c}(3) \\
105 \mathrm{~min} . \\
{[\mathrm{mm}]}\end{array}$ & $\begin{array}{c}(4) \\
150 \mathrm{~min} . \\
{[\mathrm{mm}]}\end{array}$ & $\begin{array}{c}(5) \\
195 \mathrm{~min} . \\
{[\mathrm{mm}]}\end{array}$ \\
\hline WC_S/Atq & $\mathrm{X}$ & 0,06 & 0,16 & 0,26 & 0,37 & $\mathrm{X}$ \\
Atq1_05 & $\mathrm{X}$ & 0,08 & 0,22 & 0,29 & 0,37 & $\mathrm{X}$ \\
Atq1_10 & $\mathrm{X}$ & 0,16 & 0,25 & 0,40 & $\mathrm{X}$ & $\mathrm{X}$ \\
Atq1_20 & $\mathrm{X}$ & 0,12 & 0,14 & 0,22 & 0,25 & $\mathrm{X}$ \\
Atq1_50 & $\mathrm{X}$ & 0,10 & 0,13 & 0,18 & 0,29 & $\mathrm{X}$ \\
Atq2_60 & $\mathrm{X}$ & 0,11 & 0,12 & 0,13 & 0,14 & 0,14 \\
Atq3_10 & $\mathrm{X}$ & 0,14 & 0,26 & 0,30 & 0,32 & $\mathrm{X}$ \\
Ti_120 & $\mathrm{X}$ & 0,31 & 0,44 & 0,52 & $\mathrm{X}$ & $\mathrm{X}$ \\
\hline
\end{tabular}

\section{Conclusões}

Neste trabalho foram investigadas diferentes alternativas para produção de ferramentas diamantadas com o objetivo de determinar o melhor conjunto de parâmetros de produção de ferramentas de corte para usinagem de madeira. Em todos os casos investigados foi possível depositar filmes de diamante, segundo as medidas de Raman. As medidas de tensão e os ensaios de delaminação apresentaram uma relação 
inversamente proporcional para as amostras que sofreram tratamentos químicos, sugerindo que o tensionamento da rede seja gerado pela forte ligação entre substrato e filme.

A amostra onde foi realizado um tratamento superficial de deposição de intercamadas obteve uma relação direta entre adesão e a tensão, o que pode estar ligado ao maior número de interface gerado nesta amostra.

Os ensaios de usinagem mostraram que as ferramentas Atq1_20, Atq1_50, Atq2_60 e Atq3_10 obtiveram bons resultados em relação ao substrato. Os resultados dos ensaios de usinagem em conjunto com os testes instrumentados de dureza indicam que há uma forte dependência entre os desgastes apresentados pelas ferramentas com o índice de plasticidade, sendo este efeito evidenciado nas amostras Atq1_50 e Atq2_60.

A amostra que apresentou o melhor resultado nos teste de usinagem foi a amostra Atq2_60. A amostra apresentou uma taxa de desgaste 70 \% menor que o substrato puro. Portanto, a partir de todos os resultados obtidos, no contexto deste trabalho, este tratamento superficial realizado é o mais indicado para a produção de ferramentas diamantadas para usinagem de madeira. A ferramenta produzida a partir dele apresentou elevada dureza e baixo grau de deformação plástica.

\section{Referências}

BUAINAIN, A.M.; BATALHA, M.O. 2007. Cadeia produtiva da madeira. Brasília, Gráfica e Editora Qualidade.

CABRAL, G.; GABLER, J.; LINDNER, J.; GRÁCIO, J.; POLINI, R. 2008. Diamond and Related Materials, 17:1008-1014. http://dx.doi.org/10.1016/j.diamond.2008.03.017

CAMERINI, R.V. 2008. Efeitos do processamento em altas pressões e altas temperaturas na aderência de filmes de diamante CVD depositados sobre metal duro. Porto Alegre, RS. Dissertação de Mestrado. UFRGS, $196 \mathrm{p}$.

CAMERINI, R.V.; FERREIRA, J.Z.; PEREIRA, A.S.; BALZARETTI, N.M.; FERNANDES, J.A.; SOUZA, R.B.; BLANDO, E.; HUBLER, R. 2009. Effect of high pressure and high temperature on the mechanical behavior of diamond coated WC-Co. Surface and Coatings Technology, 203:3344-3347. http://dx.doi.org/10.1016/j.surfcoat.2009.04.026

FILHO, F.C.L. 2004. Análise da usinagem da madeira visando a melhoria de processos em indústrias de móveis. Florianópolis, SC. Tese de Doutorado. UFSC, 212 p.

FRITZEN, C.L. 1996. Estudo da nucleação do diamante obtido por deposição química a vapor. Porto Alegre, RS. Tese de Doutorado, UFRGS.

GRIMSDITCH, M.H.; ANASTASSAKIS, E.; CARDONA, M. 1978. Effect of uniaxial stress on the zone-center optical phonon of diamond. Physical Review Letters B, 18(2):901-904. 
HILLIG, E. 2006. Viabilidade técnica de produção de compósitos de polietileno (HDPE) reforçados com resíduos de madeira e derivados da indústria moveleira. Curitiba, PR. Tese de Doutorado, UFPR, 193 p.

ISO 14577. Metalic Materials, Instrumented Indentation Test for Hardness and Materials Parameters, Part 1: Test Method. 5 p.

JACOBSEN, S.D. 2007. Propriedades tribocorrosivas de multicamadas Ti/TiN: dependência do comprimento de modulação e proporção da camada cerâmica. Porto Alegre, RS. Dissertação de Mestrado. PUCRS, $198 \mathrm{p}$.

KONIG, W. 1990. Fertigungsverfahren: Drehen, Fräsen, Bohren. 3a ed., Düsseldorf, VDI-Verlag GmbH, 651 p.

LUCCHESE, M.M.. 2006. Nucleação e crescimento de filmes de diamante em substratos de zircônia parcialmente estabilizada. Porto Alegre, RS. Tese de Doutorado, UFRGS, 92 p.

SANTOS, S.I. 2004. Adesão de filme auto-sustentado de diamante CVD em metal duro. Porto Alegre, RS. Tese de Doutorado, UFRGS, $112 \mathrm{p}$.

SCHROETER, R.B.; TEIXEIRA, C.R. 2000. Proposta de metodologia para medição do desgaste em ferramentas de corte de geometria definida. In: CONGRESSO NACIONAL DE ENGENHARIA MECÂNICA, 1, Natal, 2000. Anais... Natal.

SILVA, S. 1997. Recobrimento de ferramentas de corte com filmes de diamante. São Paulo, SP. Dissertação de Mestrado, USP.

TENTARDINI, E.K. 2000. Construção de um equipamento de deposição tipo magnetron sputtering e sua caracterização através de filmes finos de metais e compósitos. Porto Alegre, RS. Dissertação de Mestrado, PUCRS, 119 p.

YUHARA, D.A. 2002. Aplicação de revestimentos PVD em ferramentas de corte. Brasimet Com. Ind. S.A., São Paulo. 5 p. 